AperTO - Archivio Istituzionale Open Access dell'Università di Torino

\title{
Physiopathology of intestinal barrier and the role of zonulin
}

\section{This is the author's manuscript}

Original Citation:

Availability:

This version is available http://hdl.handle.net/2318/1707540

since 2019-08-28T17:55:08Z

Published version:

DOI:10.23736/S1120-4826.19.02554-0

Terms of use:

Open Access

Anyone can freely access the full text of works made available as "Open Access". Works made available under a Creative Commons license can be used according to the terms and conditions of said license. Use of all other works requires consent of the right holder (author or publisher) if not exempted from copyright protection by the applicable law. 


\section{Physiopathology of intestinal barrier and the role of zonulin}

Gian Paolo CAVIGLIA ${ }^{1, *}$, Chiara ROSSO ${ }^{1}$, Davide Giuseppe RIBALDONE ${ }^{2}$, Francesca DUGHERA ${ }^{1}$, Sharmila FAGOONEE ${ }^{3}$, Marco ASTEGIANO ${ }^{4}$, Rinaldo PELLICANO ${ }^{4}$

${ }^{1}$ Department of Medical Sciences, University of Turin, Turin, Italy

${ }^{2}$ Department of Surgical Sciences, University of Turin, Turin, Italy

${ }^{3}$ Institute for Biostructure and Bioimaging (CNR) c/o Molecular Biotechnology Center, Turin, Italy

${ }^{4}$ Unit of Gastroenterology, Molinette Hospital, Turin, Italy

*Corresponding author: Gian Paolo Caviglia, Department of Medical Sciences, University of Turin, Turin 10100, Italy. E-mail: caviglia.giampi@libero.it

Running title: Intestinal barrier and zonulin 


\begin{abstract}
The intestinal epithelium with its barrier function controls the antigen trafficking from the intestinal lumen to the submucosa. Zonulin, a precursor of haptoglobin-2, plays a key role in maintaining the homeostasis of the intestinal mucosa through the regulation of tight junctions, cell-cell junctions responsible of the influx of dietary and microbial antigens via paracellular route of intestinal absorption. Several studies have observed an association between zonulin levels and alteration of intestinal permeability. It is assumed that in genetically predisposed individuals, an altered intestinal permeability may induce an increased exposure to luminal antigens with consequent loss of immune tolerance, thus leading to the development and progression of various chronic inflammatory disorders. Here, we review the mechanism of intestinal permeability regulation by zonulin and the related physiopathological implications.
\end{abstract}

Key words: autoimmune diseases; intestinal permeability; microbiota. 
The intestinal mucosal barrier is a heterogeneous entity composed of physical, biochemical, and immune elements elaborated by the intestinal mucosa. The intestinal barrier has a dual role: on one hand, limits the contact with pathogens and antigens present in the intestinal lumen, and on the other hand, allows the absorption of the nutrients introduced by the diet, covering the fundamental role of homeostasis regulator of the intestinal mucosa. ${ }^{1}$

\section{The intestinal barrier}

\section{The mucus layer}

The first element that forms the intestinal barrier is the mucus layer, which covers the entire cell surface and has a protective role against the pathogens of the lumen, mechanical insults and proteolytic enzymes. In addition to the protective action, the mucus keeps the mucosa hydrated and lubricated..$^{2,3}$ The mucus is made up of proteins, carbohydrates, lipids and water, but to maintain an intact and stable layer, mucins, a family of glycoproteins, are essential. The mucins are divided into two types: the mucins secreted in the mucus, whose gene is found on chromosome 11p15.5 (MUC2, MUC5AC, MUC5B, MUC6 and MUC19) and the mucins adherent to protein receptors expressed on the cell surface (MUC1, MUC3A, MUC3B, MUC4, MUC12, MUC13, MUC15, MUC16 and MUC17). ${ }^{4,5}$ The principal mucin of the intestinal mucous layer is MUC2 and is secreted by intestinal goblet cells. ${ }^{6,7}$

The adherent mucus layer in vivo is continuous throughout the gastrointestinal tract and ranges in thickness from $300 \mu \mathrm{m}$ in the stomach and $700 \mu \mathrm{m}$ in the intestine. The lower layer is densely adherent to the epithelium, sterile in healthy subjects. Instead, the surface layer is less adherent, and colonized by bacteria. A smaller portion of mucus is also present in the intestinal crypts and is secreted directly by the Paneth cells together with antibacterial proteins, the defensins. ${ }^{2}$

Numerous studies have been carried out on the role of MUC2. In a study performed by Van der Sluis et al., ${ }^{8} \mathrm{MUC}^{-/-}$knockout mice were compared with MUC $2^{+/-}$heterozygous mice exposed to 
dextran sodium sulfate, a factor inducing colitis. The results showed that knockout mice developed colitis in 5 weeks, showing clinical symptoms and microscopic signs of inflammation compared to heterozygous mice, thus affirming that the absence of MUC2 induces colitis development. Another study by Johansson et al. ${ }^{9}$ demonstrated that in MUC2 knockout mice, the epithelial cells are in direct contact with the lumen bacteria and that these can penetrate into the crypts and also within the epithelial cells.

The transcription of mucins is a process that requires a lot of energy and is finely regulated; the genes of secreted mucins and surface mucins are both constitutively expressed and inducible by various factors. $^{2}$ The microbiota can be considered the first regulator of the expression of such genes: the bacteria present in the intestinal lumen can activate different intracellular signaling pathways that reach the nucleus and, through intranuclear mediators, modify gene expression, determining the transcription of a specific subclass of mucins. ${ }^{6}$ Another trigger capable of altering the expression of mucins is the inflammation: inflammatory mediators such as cytokines, oxidizing agents, proteases act on different signaling pathways resulting in changes in the conformation of the mucus and in the glycosylation of MUC2, as shown by several studies performed on intestinal cell cultures. ${ }^{10}$ Other stimuli that interact in this fine regulatory system are growth factors, lipids, hormones and nervous stimuli.

In addition to the mucins, in the mucous layer are present: the fc-gamma binding protein (Fcgbp), which is supposed to have the role of stabilizing the network of MUC2, ${ }^{11}$ the trefoil factor 3 (TTF3), which has been linked to protection mucosa and repair processes, ${ }^{12}$ and the phospholipid phosphatidylcholine (PC) which, through the interaction with mucins, can generate a spatial rearrangement in which the PC fatty acids move towards the intestinal lumen, generating one hydrophobic protective layer on the outer surface of the mucus. ${ }^{13}$ The elements listed up to now give the mucous layer the role of mechanical protection, and keep the lumen bacteria confined in the outer layer. 
The mucous barrier also acts as a chemical barrier to the pathogens of the lumen, preventing damage to the epithelial cells, maintaining their regular growth. ${ }^{14}$ The intestinal lumen include a complex community of pathogens that in physiological conditions lives in symbiosis with our organism, supplying nutrients and stimulating the maturation of the immune system. The antimicrobial function of mucus was first studied by Meyer-Hoffert et al. in murine models. ${ }^{15}$ In human beings, several studies have confirmed the antibacterial action of mucus towards Gram negative, Gram positive but also towards Candida albicans. Several peptides and proteins such as defensins, caltelidicins LL37, ubiquitin and members of the histone family have been identified in rectal mucus extracts. ${ }^{16}$ These studies showed that the binding of peptides and antibacterial proteins to mucus and mucins does not abolish antimicrobial activity, and that these bonds are at least partly reversible. The bonds are characterized by the electrostatic interaction between negative charges of the mucins and positive charges of the antimicrobial peptides. In physiological conditions, the microbiota itself interacts with immunity receptors located on Paneth cells, triggering the secretion of antimicrobial factors such as defensins. ${ }^{17}$ In fact, an important role in the reaction to lumen pathogens is played by innate immunity and in particular by class A immunoglobulins $(\operatorname{IgA}),{ }^{18}$ which are secreted into the mucus and prevent the passage of pathogens in the deeper layers.

\section{The epithelial layer}

The intestinal epithelium is constituted by a single cell layer that forms the luminal surface of both the small and large intestine of the gastrointestinal tract, representing a further impediment to the passage of harmful molecules from the intestinal lumen. ${ }^{19}$ The intestinal epithelium is a selective and permeable barrier: it allows the passage of water, electrolytes and nutrients from diet but prevents the passage of microorganisms and toxins. ${ }^{20}$ To allow this filter function, epithelial cells are closely connected by different protein complexes: the tight junctions, the adherent junctions, and the desmosomes. These 
intercellular connections are necessary for the mechanical cohesion of the cells, to define the boundary between the apical and basolateral region of the membrane, and also for the regulation of the permeability of the paracellular transport pathway. ${ }^{21}$

The epithelium of the small intestine is characterized by the presence of a large number of protrusions, villi and microvilli, which greatly increase the absorbent surface of this tract, and between the villi, lie the crypts of Lieberkuhn, which are invaginations rich in glands. On the contrary, the epithelium of the large intestine has a smaller surface due to the absence of this structural organization. ${ }^{22}$ The predominant cell population of the intestinal epithelium is represented by the enterocytes responsible for nutrients absorption, followed by goblet cells, enteroendocrine cells and Paneth cells. The enteroendocrine cells secrete peptide hormones involved in cell-cell tropism, tissue repair, angiogenesis and cell differentiation along the axis of crypts and villi. Paneth cells contain secretory granules which contain a large number of antimicrobial substances such as lysozyme, phospholipase A2, defensins. Paneth cells are long-lived cells and are normally confined to the small intestine, at the base of the crypts. ${ }^{23}$

In addition to these cellular populations, in the epithelial layer, especially of the small intestine, there is an epithelium responsible for the uptake of intestinal antigens, the follicole-associated epithelium (FAE). This epithelium defines the Peyer's patches, located in the lamina propria and in the submucosa, where the M cells are present, which are part of the gut-associated lymphoid tissue (GALT), that phagocyte and transport the bacterial antigens to the dendritic cells, which in turn present them to the mesenteric lymph nodes. ${ }^{24-26}$

Epithelial homeostasis is maintained by the balance between cell proliferation and apoptosis and is fundamental for the barrier function. The regulators of this fine balance are transforming growth factor (TGF)- $\alpha$, which stimulates cell proliferation, TGF- $\beta$, which inhibits it, and the Wnt/ $\beta$ catenin 
signaling pathway. ${ }^{27}$ Fevr et al. showed that the absence of $\beta$-catenin in such a signaling pathway leads to an altered stem cell maturation and a dysregulation of intestinal homeostasis. ${ }^{28}$

Epithelial cells actively participate in defense mechanisms against pathogens and show on their surface Pattern Recognition Receptors (PPRs), which have specific binding domains, to which bacteria bind and trigger intracellular signal cascades that lead to the release of cytokines, chemokines and antibacterial peptides. The two most studied families of PPRs are the nod-like receptors (NLRs) and the toll-like receptors (TLRs). These receptors also seem to be involved in the tolerance of the mucosa towards gut microbiota. ${ }^{29}$

\section{Transport through the intestinal barrier}

\section{Transcellular and paracellular pathways}

The movement of molecules, solutes and ions across the intestinal barrier occurs through two ways: the transcellular and the paracellular pathway (Figure 1). The former is the main route for nutrient absorption by means of channels and transporters, which are selective in terms of charge and size of the molecules, and are positioned on the apical and lateral side of the cell membrane. ${ }^{30}$ The latter is less selective; occurs through the intracellular spaces of intestinal cells, which are closely related to each other, and it is a passive process in which the molecules cross the barrier by diffusion, electro-diffusion and osmosis according to the gradient generated by the transcellular pathway. ${ }^{31}$ The paracellular pathway is regulated by an apical protein complex formed by tight junction, adherent junctions and desmosomes. Adherent junctions and desmosomes form strong bonds between epithelial cells and allow intercellular communication, but do not regulate paracellular permeability. The tight junctions instead surround the apical portion of the epithelial cells and regulate the paracellular permeability of solutes. In this sense, tight junctions represent both a barrier for harmful molecules and a selective passage of solutes and water. ${ }^{30,32}$ 


\section{Tight junctions and paracellular pathway}

The tight junctions are multiprotein complexes that include four families of transmembrane proteins: occludin, claudin, junctional adhesion molecules (JAMs) and tricellulin. ${ }^{33}$ The intracellular domain of these proteins interacts with cytosolic proteins, the zonula occludens $(\mathrm{ZO})$ proteins, which anchor the transmembrane proteins to the actin cytoskeleton. The interaction between the tight junctions and the actin cytoskeleton is fundamental to maintain the tight junction structure, allowing regulation of the paracellular pathway. Actin contraction and tension depends on the myosin light chain, which is phosphorylated and therefore activated by kinases such as MLC-kinase and Rho-associated kinase, determining the opening of the paracellular pathway. ${ }^{34,35}$

The c-terminal domain of occludins interacts with several intracellular proteins such as the ZO proteins, which connect them to the cytoskeleton. The role of occludin is not yet fully understood but studies on animal models indicated that they plays a crucial role in the structure of tight junctions and in the permeability of the intestinal epithelium, especially towards large molecules. In healthy epithelium, occludins are phosphorylated on threonine serine residues, and this phosphorylation allows to maintain the tight junction assembled. ${ }^{36}$

Claudins are a protein family with at least 24 members in humans and mice; each isoform is selectively expressed in tissues and cells. As for occludins, some isoforms are phosphorylated, and this regulation mechanism is useful for maintaining permeability. The extracellular portion of the claudins forms homophilic or heterophilic bonds with adjacent cells, preventing or facilitating the passage of molecules. ${ }^{37,38}$ Sonoda et al. demonstrated that the Clostridium perfringes enterotoxin binds to claudin 3 and to claudin 4 , causing the alteration of tight junctions, and thus an alteration of intestinal permeability function. ${ }^{39}$ 
JAM family belongs to the Ig superfamily; JAMs are characterized by two extracellular domains, a trans-membrane domain and a c-terminal intracellular domain. The proteins belonging to this family are expressed in various tissues, in intestinal epithelial cells JAM-A and JAM-4 are involved in the regulation of tight junctions. ${ }^{40} \mathrm{~A}$ recent study showed that JAM-A knockout mice have greater dextran permeability and increased myeloperoxidase activity, compared to wild type mice. In addition, the inflammation induced by dextran sodium sulfate was more severe in this group of mice. ${ }^{41}$ Tricellulin is a trans-membrane protein with four binding domains, two extracellular and two cytoplasmic. ${ }^{42}$ This protein plays an important role in the regulation of the epithelial barrier formed by the tight junctions, both in tricellular and bicellular junctions. Krug et al. observed that tricellulin forms a barrier for macromolecules in tricellular junctions and for all solutes in bicellular junctions. ${ }^{43}$

The proteins of the family ZO includes ZO-1, ZO-2, ZO-3, intracellular multidomain proteins that are part of the superfamily of the associated guanylate kinase and possess an inactive enzymatic guanylate-kinase like domain. These proteins bind to numerous tight junction proteins at the level of the c-terminal portion, while at the n-terminal side they bind to actin microfilaments, via proteins associated with the cytoskeleton. ${ }^{44-46}$

The opening of the tight junctions occurs in response to numerous stimuli: diet, humoral stimuli, neuronal, inflammatory markers, mast cell products and a variety of pathways that can be target of bacteria and viruses. ${ }^{47}$ In vivo and in vitro have shown that the pro-inflammatory cytokines tumor necrosis factor (TNF)- $\alpha$ and interleukin (IL)-13 can regulate this type of permeability, through 2 different pathways: a "pore pathway", more selective and based on molecules charge and size, and a "leak pathway", characterized by a lower selectivity. IL-13 increases the pore pathway leading to an increased expression of claudin $2,{ }^{48}$ while TNF- $\alpha$ increases the leak pathway via a rapid mechanism of reorganization of the tight junction involving actin microfilaments. ${ }^{49}, 50$ 


\section{Zonulin and tight junctions}

The discovery of the zonula occludens toxin (Zot), produced by Vibrio cholera, that damages the tight junction mechanism, has shed light on the mechanism involved in the modulation of the paracellular pathway. Fasano et al. showed that the terminal $\mathrm{COOH}$ portion of Zot binds to the receptor activating the proteinases 2 (PAR2), and this binding induces the activation of the intracellular signal of kinase $\mathrm{c}$ proteins $(\mathrm{PKC})$ activation that in turns induces actin microfilaments polymerization and reversible opening of tight juncions. ${ }^{51-53}$ These data suggested that Zot regulates tight junctions in a quick and reversible way; it has been hypothesized that Zot may mimic the effect of an endogenous modulator, both from a functional and an immunological point of view. The combination of purified anti-zot antibodies and the use of the Ussin chamber assay allowed to identify a human Zot homologue called zonulin. $^{54}$

Zonulin is a $47-\mathrm{kDa}$ protein, identified as pre-haptoglobin- $2,{ }^{55}$ the inactive precursor of haptoglobin-2. Haptoglobin-2, together with haptoglobin-1, is one of the two variants of human haptoglobins, which are plasma heterodimeric glycoproteins composed of $\alpha$ - and $\beta$-polypeptide chains that are covalently associated by disulfide bonds. The role of haptoglobins is to bind hemoglobin, forming stable complexes, to prevent oxidative tissue damage induced by free hemoglobin. In contrast, no biological activity was known for pre-haptoglobin-2 so far. ${ }^{56}$ Structural analysis of zonulin protein chains pointed out similarities with the structure of different growth factors. Like zonulin, growth factors are also able to alter the integrity of tight junctions. ${ }^{57}$ Zonulin by binding to PAR2 activates the epidermal growth factor receptor (EGFR) and causes the activation of an intracellular pathway that determines the activation of PKC- $\alpha$, that in turn catalyzes the phosphorylation of target proteins, such as ZO-1 and myosin 1c, and the polymerization of actin. Subsequently, the rearrangement of actin microfilaments leads to the displacement tight junction proteins. The junctional complex returns to its initial form when the binding of zonulin with the receptor ceases. ${ }^{56}$ 


\section{Role of zonulin in altered intestinal permeability}

The alteration of intestinal permeability, secondary to tight junctions derangement, has been investigated as a key feature in the etiopathogenesis of various diseases. ${ }^{57}$ In particular, in diseases with an autoimmune disorder, such as celiac disease (CD), type 1 diabetes (T1D) and multiple sclerosis, it has been showed that deranged tight junctions allow the passage of antigens from the intestinal lumen, facilitating contact with the immune system and thus triggering the immune response. It is commonly accepted that both the interaction with environmental factors and the genetic predisposition determine the aberrant immune response that preludes the onset of these diseases. Less than $10 \%$ of genetically predisposed subjects develop the disease, demonstrating the fundamental role of environmental factors. ${ }^{58}$ The antigens that pass through the intestinal barrier via paracellular pathway, interacts with different mediators of the immune response, such as antigen-presenting-cells (APCs), T and B lymphocytes. ${ }^{59}$ In genetically predisposed individuals, when the passage through the paracellular pathway of luminal antigens is increased, the immune system can lose the tolerance towards non-self-antigens, triggering the multiorgan process leading to systemic diseases. ${ }^{60}$

\section{Celiac disease}

$\mathrm{CD}$ is a unique model of disease with a relevant autoimmune component due to the knowledge acquired to date regarding its etiology: genetic predisposition is due to the expression of human leukocyte antigen (HLA) genes, with a specific autoimmune response to transglutaminases, and gliadin (a prolamin component of gluten) is the known environmental trigger. The interaction between the HLA genes and gluten determines the characteristic intestinal damage of $\mathrm{CD}$, which in physiological conditions is prevented by functioning tight junctions. ${ }^{61}$ 
In the early phases of the disease, exposure to gliadin induces an increased zonulin release determining the opening of the tight junctions, and thus increasing the passage of antigens to the submucosa, through the paracellular pathway. ${ }^{62}$ The following chain of events has been hypothesized: after ingestion of gluten, gliadin interacts with the mucosa of the small intestine causing the release of IL-8 from enterocytes, which recalls neutrophils in the lamina propria. At the same time, gliadin peptides via MYd-88 induce the release of zonulin, which allows the passage of gliadin into the submucosa, ${ }^{63}$ and the interaction with macrophages, which induce the release of pro-inflammatory cytokines such as TNF and intereferon (IFN)- $\gamma$. The presence of TNF and IFN- $\gamma$ supports and increases the mechanism triggered by zonulin of altered intestinal permeability with a further increase in the passage of antigens. ${ }^{64}$

In genetically predisposed subjects, this mechanism leads to an immune-mediated damage to the intestinal mucosa, typical of CD. With the removal of gluten from the diet, the levels of zonulin decrease, the intestine regains the barrier function and the antibody titers normalize, the autoimmune process turns off and the intestinal damage is completely repaired. ${ }^{62}$

\section{Type 1 diabetes}

Several studies have shown that the alteration of intestinal permeability is an early events associated to the development of T1D and its complications. ${ }^{65}$ Studies on animal models supporting the hypothesis of causal relationship between altered intestinal permeability and disease onset have shown that the alteration of intestinal barrier is present, and precedes both histological manifestations and symptoms development. ${ }^{66}$ The study conducted by Watts et al. investigated the expression of zonulin in BioBreeding diabetes prone (BBDP) mice compared to wild type mice. An increase in zonulin levels was observed in BBDP mice over time before symptoms onset. Subsequently, a zonulin inhibitor, AT1001, which prevents the tight junction from being disassembled, was administered to BBDP mice. 
Oral administration of AT1001 blocked the formation of autoantibodies and the alteration of intestinal permeability due to zonulin, reducing the incidence of T1D by $70 \%$. These data suggested that the increased release of zonulin was necessary for the disease onset ${ }^{67}$ A study conducted in T1D patients, showed that higher zonulin levels were observed in cases compared to healthy controls. In addition, authors observed that first-degree relatives of patients with T1D had higher serum zonulin levels compared to healthy controls, suggesting that alteration of intestinal permeability due to zonulin is a necessary but not sufficient factor for the development of T1D. ${ }^{68}$

Recently, it has been suggested an association between the concomitant presence of anti-glo-3a (a globulin present in gluten) antibodies and increased zonulin, and the risk of developing T1D in children, opening new perspectives on altered intestinal permeability mediated by zonulin and T1D onset. $^{69}$

\section{Non-alcoholic fatty liver disease}

Nonalcoholic fatty liver disease (NAFLD) is rapidly becoming the most common chronic hepatitis in Western countries and comprises a disease spectrum that ranges from simple hepatic steatosis (NAFL) to non-alcoholic steatohepatitis (NASH). ${ }^{69,70}$ The natural history comprise the characteristic features

of chronic liver damage, with fibrosis that overtime may progress to cirrhosis and its complications. ${ }^{71-73}$

There is growing evidence that alterations of gut microbiota and impairment of intestinal barrier integrity may play a role in NAFLD pathogenesis and disease progression. ${ }^{74,75}$ Pacifico et al. investigated the potential association of serum zonulin levels with the stage of liver disease in obese children with biopsy-proven NAFLD and observed that zonulin values were significantly higher in obese subjects with NAFLD that in those without (4.23 [3.18-5.89] ng/mL vs. 3.31 [2.05-4.63], $\mathrm{p}<0.01) .{ }^{76}$ In addition, zonulin was correlated with the degree of steatosis $(r=0.372, p<0.05)$ but not with lobular inflammation, ballooning and presence of NASH. Possibly, obesity may represent a 
confounding factor, considering that some reports suggested a relationship between increased zonulin levels and higher body mass index (BMI). ${ }^{77,78}$ Another study by Hendy et al. showed that serum zonulin levels were higher in non-obese adult NAFLD subjects compared to controls; moreover, zonulin levels were different among patients with NAFL compared to those with NASH $(7.60 \pm 0.91$ $\mathrm{ng} / \mathrm{mL}$ vs. $4.91 \pm 0.46, \mathrm{p}<0.001$, respectively) and were associated to elevated inflammatory markers. ${ }^{79}$ In our experience, we observed significantly higher zonulin levels in NAFLD patients compared to healthy subjects $(42.7 \mathrm{ng} / \mathrm{mL}$ vs. $8.6 \mathrm{ng} / \mathrm{mL}, \mathrm{p}<0.001)$ (Figure 2), but we did not observed any differences between patients with NAFL and those with NASH ( $\mathrm{p}=0.879)$.

\section{Autism spectrum disorder}

A correlation between autism spectrum disorders (ASDs) and gastrointestinal issues have been increasingly reported. ${ }^{80}$ To date, ASD etiology is still unknown; however, both genetic and environmental factors are likely to be implied. ${ }^{81}$ According to the leaky gut hypothesis, the increased permeability of intestinal mucosa may allow antigens from diet to pass into blood and affecting central nervous system through neuroactive peptides. ${ }^{82,83}$ Despite, available data in support of this hypothesis are still conflicting, ${ }^{84-86}$ a recent study reported higher serum zonulin levels in patients with ASD $(122.3 \pm 98.46 \mathrm{ng} / \mathrm{mL})$ compared to healthy controls $(41.89 \pm 45.83 \mathrm{ng} / \mathrm{mL})$; furthermore, zonulin levels were correlated with childhood autism rating scale $(r=0.532, p<0.001) .{ }^{87}$ Consistently, Fiorentino et al. observed that patients with ASD had reduced expression of structural proteins involved in tight junction complex compared to healthy controls. ${ }^{88}$ Taken together, these observations foster additional studies aiming at elucidate the role of zonulin in influencing gut-brain axis in patients with ASD.

\section{Inflammatory bowel diseases}


Inflammatory bowel diseases (IBD) are chronic heterogeneous disorders of the bowel resulting from environmental precipitants in genetically susceptible individuals and are distinguished in two main phenotypes, Crohn's disease and ulcerative colitis. ${ }^{89-91}$ Pathogenesis of IBD is multifactorial with immunological, genetic, microbial and environmental factors contributing to the onset of the disease. ${ }^{92}$, ${ }^{93}$ Since intestinal epithelial barrier plays a key role in regulating the interaction between antigens from the intestinal lumen and the mucosal immune system, intestinal permeability may represents an additional piece of this intricate puzzle. ${ }^{94,95}$ Studies from the animal model showed that impaired intestinal permeability represents an early event preceding disease onset; indeed, the passage of nonself-antigens in the lamina propria may trigger the immune response mediated by cytokines such as IFN- $\gamma$ and TNF- $\alpha$ which in turn may perpetuate the increased intestinal permeability, starting a vicious circle. ${ }^{96}$

Recently, we investigated serum zonulin levels in patients with IBD in comparison to healthy subjects and we observed that zonulin concentration was higher in the former group (34.5 [26.5-43.9] $\mathrm{ng} / \mathrm{mL}$ vs. $8.6[6.5-12.0] \mathrm{ng} / \mathrm{mL}, \mathrm{p}<0.001)$ showing an area under the curve of 0.98 for the discrimination between IBD patients and healthy controls. ${ }^{97}$ To note, no difference in serum zonulin concentration was observed between patients with Crohn's disease and those with ulcerative colitis $(\mathrm{p}=0.074)$ (Figure 3). In addition, we observed an inverse correlation between serum zonulin concentration and disease duration $\left(\mathrm{r}_{\mathrm{s}}=-0.30, \mathrm{p}=0.001\right) ;{ }^{97}$ this finding is consistent with the concept that altered intestinal permeability is present in IBD patients from the beginning of the disease, being this condition a necessary but not sufficient pathogenic element for disease development.

To date, only few studies investigated serum and fecal zonulin concentration in patients with IBD showing conflicting results. Malickova et al. reported higher serum and fecal zonulin values in patients with active Crohn's disease compared to ulcerative colitis. ${ }^{98}$ Our results do not support this observation; moreover, we did not find any correlation between serum and fecal zonulin concentration 
$\left(\mathrm{r}_{\mathrm{s}}=0.15, \mathrm{p}=0.394\right) .{ }^{97}$ In agreement with our findings, also Ohlsson et al. reported no correlation between zonulin concentration in serum and feces. ${ }^{99}$ Finally, Frin et al. investigated fecal zonulin as a potential predictor of response to infliximab therapy in patients with $\mathrm{UC}$, but a low accuracy was

observed. ${ }^{100}$ Likely, the measurement of zonulin in serum rather than in stool may be of greater clinical interest.

\section{Conclusions}

Zonulin is involved in the functional regulation of intestinal barrier and alterations in zonulin expression have been described in different clinical settings. A part from the above discussed diseases, several other diseases have been linked to the zonulin pathway and to the increase passage of molecules through the paracellular pathway including asthma, multiple sclerosis, glioma, ankylosing spondylitis, rheumatoid arthritis and coronary artery disease. ${ }^{56,101-104}$

In the last decades, different diagnostic methods have been proposed for the assessment of intestinal barrier integrity, including lactulose mannitol ratio test and ${ }^{51} \mathrm{Cr}$-labeled ethylenediaminetetraacetic acid $\left({ }^{51} \mathrm{Cr}\right.$-EDTA) absorption test. ${ }^{105,106}$ However, these tests have some limitations: the former is unable to assess the permeability of the colon since both lactulose and mannitol are degraded by the local microbiota, while the latter make use of a radioactive molecule. Conversely, the measurement of zonulin levels either in serum or in stool, may represent an alternative non-invasive tool to investigate the integrity of intestinal barrier.

\section{Conflict of interest}

The authors certify that there is no conflict of interest with any financial organization regarding the material discussed in the manuscript. 


\section{Financial support}

CR received research grants by Fondazione Cassa di Risparmio di Torino (2015.2643) and University of Torino (ROSC_RILO_18_01). 


\section{References}

1. Yamada T, Sartor RB, Marshall S, Specian RD, Grisham MB. Mucosal injury and inflammation in a model of chronic granulomatous colitis in rat. Gastroenterology $1993 ; 104: 759-71$.

2. McGuckin MA, Eri R, Simms LA, Florin TH, Radford-Smith. Intestinal barrier dysfunction in inflammatory bowel diseases. Inflamm bowel dis 2009;15:100-13.

3. Moran AP, Gupta A, Joshi L. Sweet-talk: role of host glycosylation in bacterial pathogenesis of the gastrointestinal tract. Gut 2011; 60:1412-1425.

4. McGuckin MA, Linden SK, Sutton P, Florin TH. Mucin dynamics and enteric pathogens. Nat Rev Microbiol 2011; 9:265-278.

5. Sheng YH, Hasnain SZ, Florin THJ, McGuckin MA. Mucins in inflammatory bowel diseases and colorectal cancer. J Gastroenterol Hepatol 2012;27:28-38.

6. Kim YS, Ho SB. Intestinal goblet cells and mucins in health and disease: recent insights and progress. Curr Gastroenterol Rep 2010;12:319-30.

7. Allen A, Hutton DA, Pearson JP. The MUC2 gene product: a human intestinal mucin. Int J Biochem Cell Biol 1998;30:797-801.

8. Van der Sluis M, De Koning BA, De Bruijn AC, Velcich A, Meijerink JP, Van Goudoever $\mathrm{JB}$, et al. Muc2-deficient mice spontaneously develop colitis, indicating that MUC2 is critical for colonic protection. Gastroenterology 2006;131:117-29.

9. Johansson ME, Phillipson M, Petersson J, Velcich A, Holm L, Hansson GC. The inner of the two Muc2 mucin-dependent mucus layers in colon is devoid of bacteria. Proc Natl Acad Sci USA 2008;105:15064-9.

10. Cornick S, Tawiah A, Chadee K. Roles and regulation of the mucus barrier in the gut. Tissue Barriers 2015;3:e982426. 
11. Johansson ME, Thomsson KA, Hansson GC. Proteomic analyses of the two mucus layers of the colon barrier reveal that their main component, the Muc2 mucin, is strongly bound to the Fcgbp protein. J Proteome Res 2009;8:3549-57.

12. Mashimo H, Wu DC, Podolsky DK, Fishman MC. Impaired defense of intestinal mucosa in mice lacking intestinal trefoil factor. Science 1996;274:262-5.

13. Stremmel W, Ehehalt R, Staffer S, Stoffels S, Mohr A, Karner M, et al. Mucosal protection by phosphatidylcholine. Dig Dis 2012;30:85-91.

14. Hill DA, Artis D. Intestinal bacteria and the regulation of immune cell homeostasis. Annu Rev Immunol 2010;28:623-67.

15. Meyer-Hoffert U, Hornef MW, Henriques-Normark B, Axelsson LG, Midtvedt T, Pütsep K, et al. Secreted enteric antimicrobial activity localises to the mucus surface layer. Gut 2008;57:764-71.

16. Antoni L, Nuding S, Weller D, Gersemann M, Ott G, Wehkamp J, et al. Human colonic mucus is a reservoir for antimicrobial peptides. J Crohns Colitis 2013;7:652-64.

17. Kinnebrew MA, Pamer EG. Innate immune signaling in defense against intestinal microbes. Immunol Rev 2012;245:113-31.

18. Macpherson AJ, Uhr T. Induction of protective IgA by intestinal dendritic cells carrying commensal bacteria. Science 2004;303:1662-5.

19. Rossi O, Meijerink M, van Baarlen P. Epithelial crosstalk at the microbiota-mucosal interface. Proc Natl Acad Sci USA 2011; 108:4607-14.

20. Groschwitz KR, Hogan SP. Intestinal barrier function: molecular regulation and disease pathogenesis. J Allergy Clin Immunol 2009;124:3-20. 
21. Michielan A, D’Incà R. Intestinal Permeability in Inflammatory Bowel Disease:

Pathogenesis, Clinical Evaluation, and Therapy of Leaky Gut. Mediators of Inflamm 2015;2015:628157.

22. Roda G, Sartini A, Zambon E, Calafiore A, Marocchi M, Caponi A, et al. Intestinal epithelial cells in inflammatory bowel diseases. World J Gastroenterol 2010;16:4264-71.

23. Bevins CL, Salzman NH. Paneth cells, antimicrobial peptides and maintenance of intestinal homeostasis. Nat Rev Microbiol 2011;9:356-68.

24. Kraehenbuhl JP, Neutra MR. Epithelial M cells: differentiation and function. Ann Rev Cell Dev Biol 2000;16:301-32.

25. Hathaway LJ, Kraehenbuhl JP. The role of M cells in mucosal immunity. Cell Mol Life Sci 2000;57:323-32.

26. Danese S. Nonimmune cells in inflammatory bowel disease: from victim to villain. Trends Immunol 2008;29:555-64.

27. Miyoshi H, Ajima R, Luo CT, Yamaguchi TP, Stappenbeck TS. Wnt5a potentiates TGF- $\beta$ signaling to promote colonic crypt regeneration after tissue injury. Science 2012;338:108-13.

28. Fevr T, Robine S, Louvard D, Huelsken J. Wnt/beta-catenin is essential for intestinal homeostasis and maintenance of intestinal stem cells. Mol Cell Biol 2007; 27:7551-9.

29. Suzuki T. Regulation of intestinal epithelial permeability by tight junctions. Cell Mol Life Sci 2013;70:631-59.

30. Tsukita S, Furuse M, Itoh M. Multifunctional strands in tight junctions. Nat Rev Mol Cell Biol 2001;2:285-93.

31. Ferraris RP, Diamond J. Regulation of intestinal sugar transport. Physiol Rev 1997;77:257302. 
32. Van Itallie CM, Anderson JM. Claudins and epithelial paracellular transport. Annu Rev Physiol 2006;68:403-29.

33. González-Mariscal L, Betanzos A, Nava P, Jaramillo BE. Tight junction proteins. Prog Biophys Mol Biol 2003;81:1-44.

34. Turner JR, Rill BK, Carlson SL, Carnes D, Kerner R, Mrsny RJ, et al. Physiological regulation of epithelial tight junctions is associated with myosin light-chain phosphorylation. Am J Physiol 1997;273:1378-85.

35. Walsh SV, Hopkins AM, Chen J, Narumiya S, Parkos CA, Nusrat A. Rho kinase regulates tight junction function and is necessary for tight junction assembly in polarized intestinal epithelia. Gastroenterology 2001;121:566-79.

36. Rao R. Occludin phosphorylation in regulation of epithelial tight junctions. Ann N Y Acad Sci 2009; 1165:62-8.

37. Tsukita S, Furuse M. Pores in the wall: claudins constitute tight junction strands containing aqueous pores. J Cell Biol 2000;149:13-6.

38. Fujibe M, Chiba H, Kojima T, Soma T, Wada T, Yamashita T, et al. Thr203 of claudin-1, a putative phosphorylation site for MAP kinase, is required to promote the barrier function of tight junctions. Exp Cell Res 2004;295:36-47.

39. Sonoda N, Furuse M, Sasaki H, Yonemura S, Katahira J, Horiguchi Y, et al. Clostridium perfringens enterotoxin fragment removes specific claudins from tight junction strands: Evidence fordirect involvement of claudins in tight junction barrier. J Cell Biol 1999;147:195-204.

40. Cunningham SA, Arrate MP, Rodriguez JM, Tran TM, Brock TA. A novel protein with homology to the junctional adhesion molecule. Characterization of leukocyte interactions. J Biol Chem 2000;275:34750-6. 
41. Laukoetter MG, Nava P, Lee WY, Severson EA, Capaldo CT, Babbin BA, et al. JAM-A regulates permeability and inflammation in the intestine in vivo. J Exp Med 2007;204:306776.

42. Ikenouchi J, Furuse M, Furuse K, Sasaki H, Tsukita S. Tricellulin constitutes a novel barrier at tricellular contacts of epithelial cells. J Cell Biol 2005;171:939-45.

43. Krug SM, Amasheh S, Richter JF, Milatz S, Gunzel D, Westphal JK, et al. Tricellulin forms a barrier to macromolecules in tricellular tight junctions without affecting ion permeability. Mol Biol Cell 1992;20:3713-24.

44. Fanning AS, Ma TY, Anderson JM. Isolation and functional characterization of the actin binding region in the tight junction protein ZO-1. FASEB J 2002;16:1835-7.

45. Haskins J, Gu L, Wittchen ES, Hibbard J, Stevenson BR. ZO-3, a novel member of the MAGUK protein family found at the tight junction, interacts with $\mathrm{ZO}-1$ and occludin. $\mathrm{J}$ Cell Biol 1998;141:199-208.

46. Anderson JM, Van Itallie CM. Physiology and Function of the Tight Junction. Cold Spring Harb Perspect Biol 2009;1:a002584.

47. Nusrat A, Turner JR, Madara JL. Molecular physiology and pathophysiology of tight junctions. IV. Regulation of tight junctions by extracellular stimuli: nutrients, cytokines, and immune cells. Am J Physiol Gastrointest Liver Physiol 2000;279:851-7.

48. Weber CR, Raleigh DR, Su L, Shen L, Sullivan EA, Wang Y, et al. Epithelial myosin light chain kinase activation induces mucosal interleukin-13 expression to alter tight junction ion selectivity. J Biol Chem 2010; 285:12037-46.

49. Shen L, Weber CR, Raleigh DR, Yu D, Turner JR. Tight junction pore and leak pathways: a dynamic duo. Annu Rev Physiol 2011;73:283-309. 
50. Heller F, Florian P, Bojarski C, Richter J, Christ M, Hillenbrand B, et al. Interleukin-13 is the key effector Th2 cytokine in ulcerative colitis that affects epithelial tight junctions, apoptosis, and cell restitution. Gastroenterology 2005;129:550-64.

51. Fasano, A. Physiological, pathological, and therapeutic implications of zonulin-mediated intestinal barrier modulation: living life on the edge of the wall. Am J Pathol 2008;173:124352.

52. Fasano A, Not T, Wang W, Uzzau S, Berti I, Tommasini A, et al. Zonulin, a newly discovered modulator of intestinal permeability, its expression in coeliac disease. Lancet 2000;358:1518-9.

53. Fasano A, Fiorentini C, Donelli G, Uzzau S, Kaper JB, Margaretten K, Ding X, Guandalini S, Comstock L, Goldblum SE. Zonula occludens toxin modulates tight junctions through protein kinase C-dependent actin reorganization, in vitro. J Clin Invest 96:710-7.

54. Wang W, Uzzau S, Goldblum SE, Fasano A. Human zonulin, a potential modulator of intestinal tight junctions. J Cell Sci 2000;113:4435-40.

55. Tripathi A, Lammers KM, Goldblum S, Shea-Donohue T, Netzel-Arnett S, Buzza MS, et al. Identification of human zonulin, a physiological modulator of tight junctions, as prehaptoglobin-2. Procl Nat Acad Sci USA 2009;106:16799-804.

56. Fasano A. Zonulin and its regulation of intestinal barrier function: the biological door to inflammation, autoimmunity, and cancer. Physiol Rev 2011; 91:151-75.

57. Drago S, El AR, Di PM, Grazia CM, Tripathi A, Sapone A, et al. Gliadin, zonulin and gut permeability: effects on celiac and non-celiac intestinal mucosa and intestinal cell line. Scand J Gastroenterol 2006;41:408-419.

58. Hewagama A, Richardson B. The genetics and epigenetics of autoimmune diseases. J Autoimmun 2009;33:3-11. 
59. Brandtzaeg P, Halstensen TS, Kett K. Immunobiology and immunopathology of human gut mucosa: humoral immunity and intraepithelial lymphocytes. Gastroenterology 1989;97:1562-84.

60. Federico A, Dallio M, Caprio GG, Ormando VM, Loguercio C. Gut microbiota and the liver. Minerva Gastroenterol Dietol 2017;63:385-98.

61. Plenge RM. Unlocking the pathogenesis of celiac disease. Nat Genet 2010;42:281-2..

62. Fasano A. Surprises from celiac disease. Sci Am 2009;301:54-61.

63. Thomas KE, Fasano A, Vogel SN. Gliadin stimulation of murine macrophage inflammatory gene expression and intestinal permeabilità are MyD88-dependent: role of the innate immune response in Celiac disease. J Immunol 2006;176:2512-21.

64. Zufferey C, Erhart D, Saurer L, Mueller C. Production of interferon-gamma by activated Tcell receptor-alphabeta CD8 alphabeta intestinal intraepithelial lymphocytes is required and sufficient for disruption of the intestinal barrier integrity. Immunology 2009;208:351-9.

65. de Kort S, Keszthelyi D, Masclee AA. Leaky gut and diabetes mellitus: what is the link? Obes Rev 2011;12:449-58.

66. Meddings JB, Jarand J, Urbanski SJ, Hardin J, Gall DG. Increased gastrointestinal permeability is an early lesion in the spontaneously diabetic BB rat. Am J Physiol. 1999;276:951-7.

67. Watts T, Berti I, Sapone A, Gerarduzzi T, Not T, Zielke R, et al. Role of the intestinal tight junction modulator zonulin in the pathogenesis of type I diabetes in BB diabetic-prone rats. Proc Natl Acad Sci U S A 2005;102:2916-21.

68. Sapone A, de Magistris L, Pietzak M, Clemente MG, Tripathi A, Cucca F, et al. Zonulin upregulation is associated with increased gut permeability in subjects with type 1 diabetes and their relatives. Diabetes 2006;55:1443-9. 
69. Younes R, Rosso C, Petta S, Cucco M, Marietti M, Caviglia GP, et al. Usefulness of the index of NASH - ION for the diagnosis of steatohepatitis in patients with non-alcoholic fatty liver: An external validation study. Liver Int 2018;38:715-23.

70. Saracco GM, Evangelista A, Fagoonee S, Ciccone G, Bugianesi E, Caviglia GP, et al. Etiology of chronic liver diseases in the Northwest of Italy, 1998 through 2014.World J Gastroenterol 2016;22:8187-93.

71. Rosso C, Caviglia GP, Abate ML, Vanni E, Mezzabotta L, Touscoz GA, et al. Cytokeratin 18-Aspartate396 apoptotic fragment for fibrosis detection in patients with non-alcoholic fatty liver disease and chronic viral hepatitis. Dig Liver Dis 2016;48:55-61.

72. Caviglia GP, Rosso C, Fagoonee S, Saracco GM, Pellicano R. Liver fibrosis: the 2017 state of art. Panminerva Med 2017;59:320-31.

73. Caviglia GP, Abate ML, Gaia S, Petrini E, Bosco C, Olivero A, et al. Risk of hepatocellular carcinoma in HBV cirrhotic patients assessed by the combination of miR-122, AFP and PIVKA-II. Panminerva Med 2017;59:283-9.

74. Federico A, Dallio M, DI Sarno R, Giorgio V, Miele L. Gut microbiota, obesity and metabolic disorders. Minerva Gastroenterol Dietol 2017;63:337-44.

75. Marengo A, Rosso C, Bugianesi E. Liver Cancer: Connections with Obesity, Fatty Liver, and Cirrhosis. Annu Rev Med 2016;67:103-17.

76. Pacifico L, Bonci E, Marandola L, Romaggioli S, Bascetta S, Chiesa C. Increased circulating zonulin in children with biopsy-proven nonalcoholic fatty liver disease. World J Gastroenterol 2014;20:17107-14.

77. Zak-Gołąb A, Kocełak P, Aptekorz M, Zientara M, Juszczyk L, Martirosian G, et al. Gut microbiota, microinflammation, metabolic profile, and zonulin concentration in obese and normal weight subjects. Int J Endocrinol 2013;2013:674106. 
78. Mörkl S, Lackner S, Meinitzer A, Mangge H, Lehofer M, Halwachs B, et al. Gut microbiota, dietary intakes and intestinal permeability reflected by serum zonulin in women. Eur J Nutr 2018;57:2985-97.

79. Hendy OM, Elsabaawy MM, Aref MM, Khalaf FM, Oda AMA, El Shazly HM. Evaluation of circulating zonulin as a potential marker in the pathogenesis of nonalcoholic fatty liver disease. APMIS 2017;125:607-13.

80. Alessandria C, Caviglia GP, Campion D, Nalbone F, Sanna C, Musso A, et al. HLA-DQ Genotyping, Duodenal Histology, and Response to Exclusion Diet in Autistic Children With Gastrointestinal Symptoms. J Pediatr Gastroenterol Nutr 2019; in press.

81. Campion D, Ponzo P, Alessandria C, Saracco GM, Balzola F. The role of microbiota in autism spectrum disorders. Minerva Gastroenterol Dietol 2018;64:333-50.

82. White JF. Intestinal pathophysiology in autism. Exp Biol Med 2003;228:639-49.

83. Zioudrou C, Streaty RA, Klee WA. Opioid peptides derived from food proteins. The exorphins. J Biol Chem 1979;254:2446-9.

84. D’Eufemia P, Celli M, Finocchiaro R, Pacifico L, Viozzi L, Zaccagnini M, et al. Abnormal intestinal permeability in children with autism. Acta Paediatr 1996;85:1076-9.

85. DeMagistris L, Familiari V, Pascotto A, Sapone A, Frolli A, Iardino P, et al. Alterations of the intestinal barrier in patients with autism spectrum disorders and in their first-degree relatives. J Pediatr Gastroenterol Nutr 2010;51:418-24.

86. Kushak RI, Buie TM, Murray KF, Newburg DS, Chen C, Nestoridi E, et al. Evaluation of intestinal function in children with autism and gastrointestinal symptoms. J Pediatr Gastroenterol Nutr 2016;62:687-91. 
87. Esnafoglu E, Cırrık S, Ayyıldız SN, Erdil A, Ertürk EY, Daglı A, et al. Increased Serum Zonulin Levels as an Intestinal Permeability Marker in Autistic Subjects. J Pediatr 2017;188:240-4.

88. Fiorentino M, Sapone A, Senger S, Camhi SS, Kadzielski SM, Buie TM, et al. Blood-brain barrier and intestinal epithelial barrier alterations in autism spectrum disorders. Mol Autism $2016 ; 7: 49$.

89. Caviglia GP, Ribaldone DG, Rosso C, Saracco GM, Astegiano M, Pellicano R. Fecal calprotectin: beyond intestinal organic diseases. Panminerva Med 2018;60:29-34.

90. Caviglia GP, Pantaleoni S, Touscoz GA, Adriani A, Rosso C, Smedile A, et al. Fecal calprotectin is an effective diagnostic tool that differentiates inflammatory from functional intestinal disorders. Scand J Gastroenterol 2014;49:1419-24.

91. Ribaldone DG, Vernero M, Saracco GM, Pellicano R, Finocchiaro F, Caviglia GP, et al. The adherence to the therapy in inflammatory bowel disease: beyond the number of the tablets. Scand J Gastroenterol 2018;53:141-6.

92. Gargallo CJ, Lué A, Gomollon F. Biosimilars in inflammatory bowel disease. Minerva Med 2017;108:239-54.

93. Ribaldone DG, Simondi D, Manca A, Demarchi B, Pulitanò R, Astegiano M, et al. Features of inflammatory bowel disease followed in a second level center in Northern Italy. Minerva Med 2017;108:481-2.

94. McGuckin MA, Eri R, Simms LA, Florin TH, Radford-Smith G. Intestinal barrier dysfunction in inflammatory bowel diseases. Inflamm Bowel Dis 2009;15:100-13.

95. Fagoonee S, Pellicano R, Actis GC. ADAM17 and gastrointestinal tract disease: clinical aspects with translational messages. Minerva Biotec 2018;30:22-8. 
96. Arrieta MC, Madsen K, Doyle J, Meddings J. Reducing small intestinal permeability attenuates colitis in the IL10 gene-deficient mouse. Gut 2009;58:41-8.

97. Caviglia GP, Dughera F, Ribaldone DG, Rosso C, Abate ML, Pellicano R, et al. Serum zonulin in patients with inflammatory bowel disease: a pilot study. Minerva Med 2019;110:95-100.

98. Malickova K, Francova I, Lukas M, Kolar M, Kralikova E, Bortlik M, et al. Fecal zonulin is elevated in Crohn's disease and in cigarette smokers. Pract Lab Med 2017;9:39-44.

99. Ohlsson B, Roth B, Larsson E, Hoglund P. Calprotectin in serum and zonulin in serum and feces after introduction of a diet with lower carbohydrate content and high fiber, fat and protein content. Biomed Rep 2017;6:411-22.

100. Frin AC, Filippi J, Boschetti G, Flourie B, Drai J, Ferrari P, et al. Accuracies of fecal calprotectin, lactoferrin, M2-pyruvate kinase, neopterin and zonulin to predict the response to infliximab in ulcerative colitis. Dig Liver Dis 2017;49:11-6.

101. Skardelly M, Armbruster FP, Meixensberger J, Hilbig H. Expression of zonulin, c-kit, glial fibrillary acidic protein in human gliomas. Transl Oncol 2009;2:117-20.

102. Ciccia F, Guggino G, Rizzo A, Alessandro R, Luchetti MM, Milling S, et al. Dysbiosis and zonulin upregulation alter gut epithelial and vascular barriers in patients with ankylosing spondylitis. Annals of the Rheumatic Diseases 2017;76:1123-32.

103. Edwards, CJ. Commensal gut bacteria and the etiopathogenesis of rheumatoid arthritis. $\mathbf{J}$ Rheumatol 2008;35:1477-9.

104. Li C, Gao M, Zhang W, Chen C, Zhou F, Hu Z, et al. Zonulin Regulates Intestinal Permeability and Facilitates Enteric Bacteria Permeation in Coronary Artery Disease. Sci Rep 2016;6:29142. 
105. Arrieta MC, Bistritz L, Meddings JB. Alterations in intestinal permeability. Gut 2006;55:1512-20.

106. Jenkins RT, Ramage JK, Jones DB, Collins SM, Goodacre RL, Hunt RH. Small bowel and colonic permeability to ${ }^{51} \mathrm{Cr}$-EDTA in patients with active inflammatory bowel disease. Clin Invest Med 1988;11:151-5. 
Figure 1. Transport of molecules through the intestinal barrier. 
Figure 2. Comparison of serum zonulin concentration between healthy control and patients with NAFLD.

HC, healthy controls; NAFLD, non-alcoholic fatty liver disease. 
Figure 3. Comparison of serum zonulin concentration in healthy control and patients with Crohn's disease and ulcerative colitis.

$\mathrm{CD}$, Crohn's disease; HC, healthy controls; UC, ulcerative colitis. 